University of Nebraska - Lincoln

DigitalCommons@University of Nebraska - Lincoln

\title{
Corn stover harvest increases herbicide movement to subsurface drains - Root Zone Water QualityModel simulations
}

\author{
Martin J. Shipitalo \\ USDA-Agricultural Research Service, National Laboratory for Agriculture and the Environment, Ames, IA, \\ martin.shipitalo@ars.usda.gov \\ Robert W. Malone \\ USDA-Agricultural Research Service, rob.malone@ars.usda.gov \\ Liwang Ma \\ USDA-ARS \\ Bernard T. Nolan \\ US Geological Survey \\ Rameshwar S. Kanwar \\ lowa State University \\ See next page for additional authors
}

Follow this and additional works at: https://digitalcommons.unl.edu/usdaarsfacpub

Shipitalo, Martin J.; Malone, Robert W.; Ma, Liwang; Nolan, Bernard T.; Kanwar, Rameshwar S.; Shaner, Dale L.; and Pederson, Carl H., "Corn stover harvest increases herbicide movement to subsurface drains Root Zone Water QualityModel simulations" (2015). Publications from USDA-ARS / UNL Faculty. 1541. https://digitalcommons.unl.edu/usdaarsfacpub/1541

This Article is brought to you for free and open access by the U.S. Department of Agriculture: Agricultural Research Service, Lincoln, Nebraska at DigitalCommons@University of Nebraska - Lincoln. It has been accepted for inclusion in Publications from USDA-ARS / UNL Faculty by an authorized administrator of DigitalCommons@University of Nebraska - Lincoln. 


\section{Authors}

Martin J. Shipitalo, Robert W. Malone, Liwang Ma, Bernard T. Nolan, Rameshwar S. Kanwar, Dale L. Shaner, and Carl H. Pederson 


\title{
Corn stover harvest increases herbicide movement to subsurface drains - Root Zone Water Quality Model simulations
}

\author{
Martin J Shipitalo, ${ }^{\mathrm{a}^{*}}$ Robert W Malone, ${ }^{\mathrm{a}}$ Liwang Ma, ${ }^{\mathrm{b}}$ Bernard T Nolan, ${ }^{\mathrm{c}}$ \\ Rameshwar S Kanwar, ${ }^{d}$ Dale L Shaner ${ }^{b}$ and Carl H Pederson ${ }^{d}$
}

\begin{abstract}
BACKGROUND: Crop residue removal for bioenergy production can alter soil hydrologic properties and the movement of agrochemicals to subsurface drains. The Root Zone Water Quality Model (RZWQM), previously calibrated using measured flow and atrazine concentrations in drainage from a 0.4 ha chisel-tilled plot, was used to investigate effects of 50 and $100 \%$ corn (Zea mays L.) stover harvest and the accompanying reductions in soil crust hydraulic conductivity and total macroporosity on transport of atrazine, metolachlor and metolachlor oxanilic acid (OXA).

RESULTS: The model accurately simulated field-measured metolachlor transport in drainage. A 3 year simulation indicated that $50 \%$ residue removal reduced subsurface drainage by $31 \%$ and increased atrazine and metolachlor transport in drainage 4-5-fold when surface crust conductivity and macroporosity were reduced by $\mathbf{2 5} \%$. Based on its measured sorption coefficient, approximately twofold reductions in OXA losses were simulated with residue removal.

CONCLUSION: The RZWQM indicated that, if corn stover harvest reduces crust conductivity and soil macroporosity, losses of atrazine and metolachlor in subsurface drainage will increase owing to reduced sorption related to more water moving through fewer macropores. Losses of the metolachlor degradation product OXA will decrease as a result of the more rapid movement of the parent compound into the soil.
\end{abstract}

Published 2015. This article is a U.S. Government work and is in the public domain in the USA.

Keywords: atrazine; metolachlor; modeling; OXA; tile drainage; water quality

\section{INTRODUCTION}

A goal has been established to replace $30 \%$ of the current US petroleum consumption with biomass-derived fuels by $2030 .{ }^{1}$ In order to achieve this target; biomass will have to be obtained from multiple feedstocks, including forestry resources, crop residues and specifically grown bioenergy crops. In terms of crop residues, the above-ground material left in the field after harvest of corn grain, consisting of leaves, stalks and cobs, collectively referred to as corn stover, has been identified as a major potential contributor to the estimated billion tons of biomass needed to reach this objective. ${ }^{1-3}$

Crop residues, however, provide numerous ecosystem services and should not be considered a waste product. ${ }^{4-6}$ These functions include reducing wind and water erosion, replenishing soil organic carbon and returning nutrients to the soil. ${ }^{6}$ Thus, the amount that can be sustainably removed is limited by these environmental and agronomic constraints. For example, Blanco-Canqui et al. ${ }^{7}$ observed negative effects on soil physical properties when more than $25 \%$ of the stover was removed from some continuous no-till corn fields in Ohio, whereas Sheehan et al. ${ }^{8}$ posit that negative effects can be avoided when up to $70 \%$ is removed from no-till fields in lowa.

When left on the surface, crop residues protect soil from raindrop impact and enhance aggregate stability by increasing soil organic carbon content. Consequently, partial or complete removal of crop residues can contribute to a decline in soil aggregate stability and increased strength and formation of soil crusts, which contribute to reduced hydraulic conductivity and infiltration rates. ${ }^{4}$ Additionally, retention of surface residues can result in a cooler and wetter environment, which can increase earthworm activity and populations compared with situations in which residues are incorporated by tillage., ${ }^{9,10}$ This was shown to be the case by Blanco-Canqui et $a l^{7}{ }^{7}$ when they noted that earthworm midden numbers, an indirect measure of earthworm populations, were 6-14 times greater when corn stover was retained than when it was completely removed in one harvest cycle. A smaller reduction in measured earthworm numbers (32\%) was noted by Karlen et al. ${ }^{11}$ after 10 years of complete stover removal.

\footnotetext{
* Correspondence to: Martin J Shipitalo, USDA-Agricultural Research Service, National Laboratory for Agriculture and the Environment, 2110 University Boulevard, Ames, IA 50011-3120, USA.E-mail: martin.shipitalo@ars.usda.gov

a USDA-Agricultural Research Service, Ames, IA, USA

b USDA-Agricultural Research Service, Fort Collins, CO, USA

c US Geological Survey, Reston, VA, USA

d lowa State University, Ames, IA, USA
} 
The reduction in earthworm populations as a result of residue removal, in turn, can result in decreased macropore formation. ${ }^{4}$ This loss of biologically produced macropores can also reduce soil hydraulic conductivity and influence the fate of surface-applied agrochemicals. ${ }^{12}$ Water flows at a greater velocity and to a greater depth through macropores than when the entire soil matrix contributes to flow. This reduces the amount of soil that entrained solutes encounter and the contact time with the soil, which reduces solute sorption. Thus, macropore flow can contribute to increased leaching, particularly of strongly sorbed solutes. ${ }^{12,13}$

Among agrochemicals of particular concern for leaching are atrazine [2-chloro-4-(ethylamino)-6-isopropylamino)-s-triazine] and metolachlor [2-chloro- $N$-(2-ethyl-6-methylphenyl)- $N$ (methoxy-1-methylethyl)acetamide], which are predominately used to control weeds in corn. ${ }^{14}$ These are two of the four most frequently detected pesticides in groundwater in agricultural and urban areas reported by the US Geological Survey as part of their national assessment of pesticides in streams and groundwater. ${ }^{14}$ Similarly, within lowa, these are the most frequently detected herbicides in groundwater. ${ }^{15}$

The fate of herbicide degradates also needs to be considered in order fully to understand the environmental impact of corn stover harvest. Sorption studies have suggested that two breakdown products of metolachlor are more mobile than the parent compound and are more likely to contaminate surface and groundwater. ${ }^{16}$ Likewise, the USEPA ${ }^{17}$ considered metolachlor to be moderately to highly mobile and the degradation product metolachlor oxanilic acid (OXA) \{2-[(2-ethyl-6-methylphenyl)(2-methoxy-1-methylethyl)amino]2-oxoacetic acid\} to be extremely mobile. In lowa, two of the top three herbicide compounds most frequently detected in groundwater were metabolites of metolachlor. ${ }^{18}$ In contrast, atrazine was detected more frequently than any of its transformation products.

Thus, in order more fully to assess the environmental impact of corn stover harvest, the effects on water movement and the transport of herbicides and their degradates to subsurface drains need to be considered in light of its direct effects on soil crusting, earthworm populations and soil macroporosity. A cost-effective method to accomplish this objective, which is hard to achieve experimentally because field data are often sparse and difficult to collect, is to use a model that incorporates effects of management, weather and soil properties on the movement of pesticides and their breakdown products, considering degradation, sorption and macropore flow. ${ }^{19-21}$

The Root Zone Water Quality Model (RZWQM) incorporates these elements and has been successfully tested and used to simulate pesticide and pesticide metabolite fate and transport in numerous field and laboratory studies. ${ }^{19,22,23}$ Furthermore, the RZWQM has recently been used for accurate simulation of metolachlor and OXA fate in widely different soil and climatic conditions in Maryland and Nebraska. ${ }^{24}$ Therefore, our objective was to combine measured weather data with information on atrazine and metolachlor concentrations in subsurface drain flow and the sorption characteristics of these herbicides and OXA from an experimental plot in lowa to predict the impact of stover harvest on losses of these compounds in drain flow.

\section{MATERIALS AND METHODS}

\subsection{Plot management and data collection}

Data from a long-term, tilled plot (plot 13) at the lowa State University Northeastern Research Center near Nashua, lowa, were used in the study. Flow from a $10 \mathrm{~cm}$ diameter, plastic, subsurface drain line installed in the center of the 0.4 ha plot at a depth of 120 $\mathrm{cm}$ in 1979 was directed into a sump so that water samples could be periodically collected and flow rate electronically monitored year round. Two drain lines installed on the borders of the plot parallel to the center drain line and a $10 \mathrm{~m}$ wide uncultivated buffer between adjacent plots helped to minimize cross-contamination. Soils in the plot consisted of somewhat poorly drained Floyd loam (fine-loamy, mixed, superactive, mesic Aquic Pachic Hapludoll) and Readlyn loam (fine-loamy, mixed, superactive, mesic Aquic Hapludoll) developed in sediment overlying glacial till. Maximum slope in plot 13 was $<2 \%$, and surface run-off was not measured but was reportedly minimal, based on measurements made at other plots at the site. ${ }^{25}$ Soil samples were taken 4-5 times each year to depths of up to $60 \mathrm{~cm}$ to determine the amount of metolachlor retained in the soil. Further details on plot design, operation and soil properties can be found in Kanwar et al., ${ }^{26}$ Kumar et $a ._{.}{ }^{27}$ and Malone et $a .^{28}$ and in the online database available at http://apps.tucson.ars.ag.gov/nashua/.

Subsurface flow data for six calendar years (1990-1995) and measured herbicide concentrations in drain flow from 1993 to 1995 were used in this study. Corn was planted in May of each year, and post-harvest the plot was moldboard plowed for the first three years and chisel tilled in subsequent years, except in 1991 when wet soil conditions precluded plowing until the following spring. Atrazine $\left(0.6 \mathrm{~kg} \mathrm{Al} \mathrm{ha}^{-1}\right)$ and metolachlor $\left(2.8 \mathrm{~kg} \mathrm{Al} \mathrm{ha}^{-1}\right)$ were applied on 17 May 1993, 2 May 1994 and 16 May 1995 at planting. Atrazine was applied prior to 1993 , but metolachlor was not used from 1990 to 1992. For the first 60 days after application, samples for herbicide analysis were collected 3 times a week when there was flow from the drain and composited weekly for analysis. After 60 days, sampling frequency was reduced to once a week if there was flow. Weather data, including hourly rainfall, solar radiation and daily minimum and maximum temperatures, were obtained from an on-site station and supplemented with lowa Mesonet data. $^{28}$

\subsection{Model parameterization and calibration}

We used the RZWQM (v.2.4), a one-dimensional, vertical model that simulates crop management, plant growth and movement of water, nutrients and pesticides in surface run-off, into groundwater and through subsurface drainage. During infiltration, the model divides the soil into $1 \mathrm{~cm}$ depth increments, and this water is assigned the same chemical characteristics as overland flow. Manual and automated parameter optimization was achieved by linking the RZWQM to PEST: Model Independent Parameter Estimation. ${ }^{29}$ The calibrated parameters used were exactly the same as those reported for this same plot (plot 13) by Malone et $a{ }^{28}$ in a study in which effects of tillage and herbicide application rate on atrazine movement to subsurface drains were investigated. In that study, the investigators noted that the atrazine sorption coefficient was the most sensitive parameter affecting its concentration in tile flow. Therefore, we collected four replicate surface horizon soil samples from the plot and used a batch-slurry technique to determine sorption coefficients $\left(K_{d}\right)$ for metolachlor and OXA. ${ }^{30}$ Measured sorption coefficients were divided by soil organic carbon contents, determined using a combustion furnace, to obtain the organic partition coefficients $\left(K_{\mathrm{oc}}\right)$. The $K_{\mathrm{oc}}$ for metolachlor $\left(200 \mathrm{~mL} \mathrm{~g}^{-1}\right)$ was similar to the PEST-calibrated metolachlor $K_{\mathrm{oc}}\left(187 \mathrm{~mL} \mathrm{~g}^{-1}\right)$ obtained by Nolan et al. ${ }^{24}$ for a field site in Nebraska, whereas our measured value for OXA $\left(57 \mathrm{~mL} \mathrm{~g}^{-1}\right)$ was substantially higher than their calibrated value of $14 \mathrm{~mL} \mathrm{~g}^{-1}$. These 
differences in sorption coefficients are not unusual, given differences in soils among these sites.

The RZWQM simulates pesticide removal from plant residue using two wash-off parameters. ${ }^{31}$ The same parameters (wash-off fraction $100 \%$, wash-off power term $0.033 \mathrm{~mm}^{-1}$ ) were used for metolachlor and OXA as for atrazine, based on RZWQM simulations in which atrazine losses were compared with field-measured leaching. ${ }^{28}$ These same values have also been successfully used with the RZWQM to simulate measured leaching and run-off losses of metribuzin. ${ }^{32}$ The pesticide half-life on crop residue was assumed to be less than in soil, as suggested by Wauchope et al. ${ }^{31}$

The calibrated model was used to investigate effects of nominal 0,50 and $100 \%$ removal of corn stover. At the 50 and $100 \%$ removal levels, the model was run under four scenarios. In the simplest scenario, the only adjustment to model parameterization was corn stover removal when the grain was harvested. In the second scenario, the surface crust conductivity was reduced by $25 \%$ for the $50 \%$ residue removal and by $50 \%$ when all the corn stover was harvested (Table 1). Likewise, in the third scenario, total soil macroporosity was reduced by $25 \%$ for the $50 \%$ residue removal and by $50 \%$ when all the corn stover was harvested. In the final scenario, both surface crust conductivity and macroporosity were reduced by the specified amounts with residue removal. In order to compare the effect of these management scenarios on herbicide losses, atrazine application rate prior to 1993 was set to zero to eliminate carryover, and the application rate for the simulated years (1993-1995) was increased to $2.8 \mathrm{~kg} \mathrm{Al} \mathrm{ha}^{-1}$ to match the actual rate of metolachlor addition. Atrazine was applied to plot 13 at this rate from 1990 to 1992 (http://apps.tucson.ars.ag.gov/nashua/), and $2.8 \mathrm{~kg} \mathrm{Al} \mathrm{ha}^{-1}$ is within label requirements.

\section{RESULTS AND DISCUSSION}

\subsection{Simulated residue levels}

Models employed by three US agencies using different assumptions all predict that lowa will be a major supplier of corn stover for biofuel production. ${ }^{2}$ The amount of stover that can be sustainably harvested, however, is likely to be less than the nominal $100 \%$ level we simulated. Nevertheless, even at this level there was still a considerable amount of residue retained after harvest. While the amount of residue retained varied from year to year owing to weather-related differences in crop growth, the average standing and surface residue for the 3 year period (1993-1995) with $100 \%$ removal was $1440 \mathrm{~kg} \mathrm{ha}^{-1}$ (Table 2).

As Johnson et al. ${ }^{33}$ have conclusively demonstrated, a universal minimum residue amount to maintain soil health and organic carbon levels is a flawed concept. Nevertheless, they suggested retaining $6000 \mathrm{~kg} \mathrm{ha}^{-1}$ year $^{-1}$ as a useful generic starting point on which to base harvest recommendations, although less residue may be required for erosion control. With this rate in mind, the $50 \%$ nominal harvest rate resulted in sufficient residue in all years, except 1994, when limited crop growth resulted in barely enough residue to meet the target even with no residue removal (Table 2 ). At the $100 \%$ harvest level, the amount of standing and surface biomass at harvest was well below the threshold in all three years (Table 2).

\subsection{Measured and simulated drainage volume}

As pointed out by Malone et al. ${ }^{19}$ and others, a model must first correctly simulate hydrology in order accurately to predict pesticide transport. The measured timing of water exiting the
Table 1. Modeled scenarios and rate of surface biomass harvest, surface crust conductivity and total macroporosity used in the RZWQM simulations

\begin{tabular}{|c|c|c|c|}
\hline Scenario & $\begin{array}{l}\text { Above-ground } \\
\text { biomass } \\
\text { harvest (\%) }\end{array}$ & $\begin{array}{c}\text { Surface } \\
\text { crust } \\
K_{\mathrm{s}}\left(\mathrm{cm} \mathrm{h}^{-1}\right)\end{array}$ & $\begin{array}{c}\text { Total } \\
\text { macroporosity } \\
\left(\mathrm{cm}^{3} \mathrm{~cm}^{-3}\right)\end{array}$ \\
\hline Control - residue intact ${ }^{a}$ & 0 & 0.0530 & 0.00053 \\
\hline $50 \%$ Biomass removal $^{\mathrm{b}}$ & 75 & 0.0530 & 0.00053 \\
\hline $\begin{array}{l}50 \% \text { Biomass } \\
\text { removal - reduced } \\
\text { crust conductivity }\end{array}$ & 75 & 0.0397 & 0.00053 \\
\hline $\begin{array}{l}50 \% \text { Biomass } \\
\text { removal - reduced } \\
\text { macroporosity }\end{array}$ & 75 & 0.0530 & 0.00040 \\
\hline $\begin{array}{l}\text { 50\% Biomass } \\
\text { removal - reduced } \\
\text { conductivity and } \\
\text { macroporosity }\end{array}$ & 75 & 0.0397 & 0.00040 \\
\hline $100 \%$ Biomass removal $^{c}$ & 97 & 0.0530 & 0.00053 \\
\hline $\begin{array}{l}\text { 100\% Biomass } \\
\text { removal - reduced } \\
\text { crust conductivity }\end{array}$ & 97 & 0.0265 & 0.00053 \\
\hline $\begin{array}{l}\text { 100\% Biomass } \\
\text { removal - reduced } \\
\text { macroporosity }\end{array}$ & 97 & 0.0530 & 0.00026 \\
\hline $\begin{array}{l}\text { 100\% Biomass } \\
\text { removal - reduced } \\
\text { conductivity and } \\
\text { macroporosity }\end{array}$ & 97 & 0.0265 & 0.00026 \\
\hline
\end{tabular}

a All management and RZWQM input parameters of this scenario are identical to those used for this plot in Malone et al., ${ }^{28}$ except for the atrazine application, which was changed to $2.8 \mathrm{~kg} \mathrm{Al} \mathrm{ha}^{-1}$ in 1993-1995 and eliminated in previous years.

${ }^{b}$ Nominal $50 \%$ simulated above-ground biomass removal was achieved in RZWQM by leaving $15 \mathrm{~cm}$ of standing residue and applying a harvest index of 75 to the remaining surface residue. Parameters other than those indicated were identical to those used in the control. ${ }^{c}$ Nominal $100 \%$ simulated above-ground biomass removal was achieved in RZWQM by leaving $15 \mathrm{~cm}$ of standing residue and applying a harvest index of 97 to the remaining surface residue. Parameters other than those indicated were identical to those used in the control.

subsurface drains closely corresponded to the simulated timing with drainage starting in late March to early June, depending on weather year (Fig. 1). Likewise, the measured amount of drainage varied considerably, with 1993 the wettest year, having 5.5 times more drainage than the driest year (1994). In most years, the RZWQM slightly underpredicted the drainage volume, and for the 6 year period average, annual, simulated drainage volume $(16.0 \mathrm{~cm})$ was $19 \%$ less than the measured volume $(19.7 \mathrm{~cm})$. The Nash-Sutcliffe efficiency (EF) was 0.56 , indicating an acceptable fit of the model to the measured drainage volume. According to Moriasi et al., ${ }^{34} \mathrm{EF}$ values greater than 0.5 are indicative of a satisfactory simulation of measured data.

In each of the three years (1993-1995) in which herbicide losses were measured, simulated harvesting of the corn stover reduced drainage volume mainly owing to increased evaporation from the soil surface, but had little effect on surface run-off (Table 3). Removal of surface residue at the $50 \%$ rate reduced average subsurface drainage by $31 \%$ compared with leaving the residue intact while increasing evaporation by $38 \%$ (Table 3 ). Reducing the surface crust conductivity, the total macroporosity or both by $25 \%$ only had a minimal effect on net water movement to 
Table 2. Effect of residue harvest on the amount of standing and surface biomass at harvest and at the time of herbicide application

\begin{tabular}{|c|c|c|c|c|c|c|}
\hline \multirow[b]{2}{*}{ Crop year } & \multicolumn{2}{|c|}{ Control - no residue removed } & \multicolumn{2}{|c|}{$50 \%$ Biomass removal } & \multicolumn{2}{|c|}{$100 \%$ Biomass removal } \\
\hline & $\begin{array}{c}\text { Modeled at } \\
\text { harvest }^{\mathrm{a}}\left(\mathrm{kg} \mathrm{ha}^{-1}\right)\end{array}$ & $\begin{array}{c}\text { Modeled at } \\
\text { planting }^{\mathrm{b}}\left(\mathrm{kg} \mathrm{ha}^{-1}\right)\end{array}$ & $\begin{array}{c}\text { Modeled at } \\
\text { harvest }\left(\mathrm{kg} \mathrm{ha}^{-1}\right)\end{array}$ & $\begin{array}{c}\text { Modeled at } \\
\text { planting }\left(\mathrm{kg} \mathrm{ha}^{-1}\right)\end{array}$ & $\begin{array}{c}\text { Modeled at } \\
\text { harvest }\left(\mathrm{kg} \mathrm{ha}^{-1}\right)\end{array}$ & $\begin{array}{c}\text { Modeled at } \\
\text { planting }\left(\mathrm{kg} \mathrm{ha}^{-1}\right)\end{array}$ \\
\hline 1993 & 16830 & 12670 & 7380 & 5360 & 2010 & 1500 \\
\hline 1994 & 6410 & 4850 & 2480 & 1840 & 790 & 600 \\
\hline 1995 & 14720 & 9550 & 6150 & 3740 & 1510 & 960 \\
\hline Average & 12650 & 9020 & 5340 & 3650 & 1440 & 1020 \\
\hline
\end{tabular}

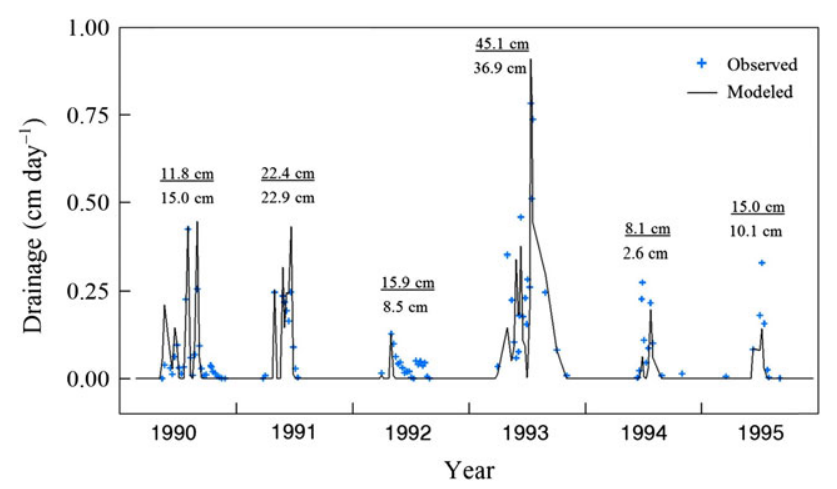

Figure 1. Weekly averaged, daily observed and RZWQM-predicted subsurface drainage rate from chisel-tilled plot 13 in Nashua, lowa. The top number above each year is the measured annual flow volume, with the modeled volume beneath.

the drains, with a maximum additional reduction in drainage of $0.4 \%$. Similarly, the effect on evaporation and run-off was negligible. Likewise, removal of all residue reduced drainage by $43 \%$ compared with the control, and reducing the soil hydraulic properties only reduced the subsurface drainage by an additional $1.8 \%$. Thus, the first increment in residue removal had a much greater effect on drainage volume than removing the next $50 \%$, while changing the hydraulic properties had a minimal effect on drainage volume.

\subsection{Measured and simulated metolachlor in drainage water and soil}

In addition to its sorption coefficient, metolachlor half-life is a critical parameter affecting its fate in soil and water. The RZWQM adjusts pesticide degradation on a daily basis using simulated soil temperature and water content. Therefore, we adjusted the soil degradation coefficient in the RZWQM at $20^{\circ} \mathrm{C}$ and $33 \%$ soil water content to achieve an acceptable fit $\left(r^{2}=0.67\right)$ between observed and simulated metolachlor concentrations in the soil (Fig. 2). This resulted in a metolachlor half-life for the entire soil profile and crop residue for May through September that averaged 31 days for 1993-1995. This falls within the range of 15-70 days reported for metolachlor in Extoxnet (http://extoxnet.orst.edu/pips/metolach.htm).

The calibrated model has been previously shown accurately to predict atrazine concentrations in the soil and in subsurface drainage from this plot. ${ }^{28}$ Similarly, our simulations of weekly, flow-weighted metolachlor concentrations using identical model parameterization and site-specific measured metolachlor $K_{\text {oc }}$ followed the general pattern of measured concentrations in the subsurface drainage water (Fig. 3). The highest measured and simulated concentrations were noted in 1993 and coincided with the peak in drain flow. The model tended to underpredict the measured concentrations early in the growing season and overpredict later in the year.

The measured cumulative metolachlor transport in drainage was more closely simulated than the weekly concentration in most years (Fig. 4). In 1993, however, simulated transport (4.03 $\mathrm{g} \mathrm{ha}^{-1}$ ) was nearly double that of measured transport $\left(2.03 \mathrm{~g} \mathrm{ha}^{-1}\right)$. Most of this discrepancy was due to a single week in late August when the RZWQM predicted an average metolachlor concentration of $1.6 \mu \mathrm{g}$ $\mathrm{L}^{-1}$ in the drain flow when none was detected in the composite sample collected that week (Fig. 3). If this sampling period is treated as an outlier and eliminated, the simulated transport (2.11 $\mathrm{g} \mathrm{ha}^{-1}$ ) closely approximates the measured value, with an EF of 0.89 in 1993 and 0.54 in 1994 and 1995. The greater measured and simulated transport in 1993 than in 1994 and 1995 was due to greater drainage volume in addition to the timing and intensity of rainfall relative to the metolachlor application. Thus, the model previously calibrated using observed flow volumes and atrazine concentrations in tile drainage by Malone et al. ${ }^{28}$ accurately predicted the fate of metolachlor in tile drainage and in the soil.

\subsection{Effect of residue harvest on herbicides in tile flow}

In all scenarios, herbicide losses in subsurface drainage were much greater in 1993 than in 1994 and 1995 (Table 3). This coincided with the much greater measured and simulated drainage volume in 1993 (Fig. 1). Averaged over the 3 year period with no removal of residue, simulated metolachlor losses were about 1.8 times greater than losses of atrazine. Most of this difference was probably due to atrazine having a higher calibrated $K_{\mathrm{oc}}\left(244.5 \mathrm{~mL} \mathrm{~g}^{-1}\right)$ than our measured $K_{\text {oc }}$ for metolachlor $\left(200 \mathrm{~mL} \mathrm{~g}^{-1}\right)$, as $K_{\text {oc }}$ was the most sensitive parameter according to Malone et al. ${ }^{28}$

In contrast to the two herbicides, predicted OXA losses in drain flow were not strongly correlated with drainage volume when the residue layer was left intact. The loss in 1995 was similar in magnitude to that in 1993, although the measured and simulated drainage volume was approximately 3 times greater in 1993 (Table 3 and Fig. 1). This suggested that in 1995 the timing and rate of OXA formation led to it being more available for leaching than in 1993 when drainage volumes were greater. Additionally, OXA losses were much greater in each year than either its parent compound, metolachlor, or atrazine (Table 3). This is congruent 
Table 3. Effect of residue removal and reduced crust hydraulic conductivity and soil macroporosity on drainage, evaporation, surface run-off and losses of atrazine, metolachlor and OXA in tile flow in 1993, 1994 and 1995

\begin{tabular}{|c|c|c|c|c|c|c|c|c|c|}
\hline \multirow[b]{2}{*}{ Year } & \multirow[b]{2}{*}{$\begin{array}{l}\text { Control } \\
\text { Residue } \\
\text { intact }\end{array}$} & \multicolumn{4}{|c|}{ 50\% Biomass removal } & \multicolumn{4}{|c|}{$100 \%$ Biomass removal } \\
\hline & & $\begin{array}{l}\text { Residue } \\
\text { removal only }\end{array}$ & $\begin{array}{l}\text { Reduced crust } \\
\text { conductivity }\end{array}$ & $\begin{array}{c}\text { Reduced } \\
\text { macroporosity }\end{array}$ & $\begin{array}{c}\text { Reduced } \\
\text { conductivity } \\
\text { and macroporosity }\end{array}$ & $\begin{array}{l}\text { Residue } \\
\text { removal } \\
\text { only }\end{array}$ & $\begin{array}{l}\text { Reduced crust } \\
\text { conductivity }\end{array}$ & $\begin{array}{c}\text { Reduced } \\
\text { macroporosity }\end{array}$ & $\begin{array}{c}\text { Reduced } \\
\text { conductivity and } \\
\text { macroporosity }\end{array}$ \\
\hline \multicolumn{10}{|c|}{ Drainage $(\mathrm{cm})$} \\
\hline 1993 & 36.9 & 29.3 & 29.2 & 29.3 & 29.3 & 24.6 & 24.6 & 24.6 & 24.6 \\
\hline 1994 & 2.6 & 1.4 & 1.3 & 1.3 & 1.4 & 1.2 & 0.8 & 1.2 & 0.6 \\
\hline 1995 & 10.1 & 3.3 & 3.3 & 3.3 & 3.2 & 2.3 & 2.2 & 2.2 & 2.1 \\
\hline Total & 49.6 & 34.0 & 33.9 & 33.9 & 33.8 & 28.1 & 27.6 & 28.0 & 27.2 \\
\hline \multicolumn{10}{|c|}{ Evaporation $(\mathrm{cm})$} \\
\hline 1993 & 25.0 & 37.7 & 37.6 & 37.6 & 37.7 & 46.2 & 46.0 & 46.2 & 45.8 \\
\hline 1994 & 28.5 & 34.0 & 33.8 & 33.8 & 34.0 & 34.7 & 34.7 & 34.9 & 34.6 \\
\hline 1995 & 19.7 & 29.5 & 29.6 & 29.5 & 29.6 & 33.1 & 33.1 & 33.1 & 33.0 \\
\hline Total & 73.3 & 101.2 & 101.0 & 101.0 & 101.3 & 114.0 & 113.8 & 114.2 & 113.4 \\
\hline \multicolumn{10}{|c|}{ Run-off (cm) } \\
\hline 1993 & 8.0 & 6.9 & 7.1 & 7.0 & 7.0 & 6.7 & 6.8 & 6.8 & 6.8 \\
\hline 1994 & 3.0 & 3.2 & 3.3 & 3.3 & 3.5 & 3.1 & 4.0 & 3.3 & 5.0 \\
\hline 1995 & 3.9 & 3.9 & 3.8 & 3.9 & 4.0 & 3.9 & 3.9 & 4.2 & 4.3 \\
\hline Total & 14.9 & 14.0 & 14.2 & 14.1 & 14.4 & 13.8 & 14.7 & 14.3 & 16.1 \\
\hline \multicolumn{10}{|c|}{ Atrazine $\left(\mathrm{g} \mathrm{ha}^{-1}\right)$} \\
\hline 1993 & 1.65 & 0.83 & 2.36 & 1.86 & 9.28 & 0.64 & 4.59 & 6.70 & 36.46 \\
\hline 1994 & 0.09 & 0.01 & 0.08 & 0.08 & 0.46 & 0.01 & 0.14 & 0.35 & 0.85 \\
\hline 1995 & 0.80 & 0.08 & 0.27 & 0.29 & 0.99 & 0.04 & 0.39 & 0.56 & 2.21 \\
\hline Total & 2.54 & 0.93 & 2.71 & 2.23 & 10.73 & 0.69 & 5.12 & 7.61 & 39.52 \\
\hline \multicolumn{10}{|c|}{ Metolachlor $\left(\mathrm{g} \mathrm{ha}^{-1}\right)$} \\
\hline 1993 & 4.03 & 1.47 & 7.35 & 5.55 & 23.53 & 0.86 & 12.43 & 11.73 & 34.94 \\
\hline 1994 & 0.19 & 0.02 & 0.15 & 0.12 & 0.61 & 0.01 & 0.20 & 0.28 & 0.39 \\
\hline 1995 & 0.33 & 0.02 & 0.11 & 0.10 & 0.38 & 0.01 & 0.14 & 0.14 & 0.35 \\
\hline Total & 4.55 & 1.51 & 7.61 & 5.77 & 24.52 & 0.88 & 12.77 & 12.15 & 35.67 \\
\hline \multicolumn{10}{|c|}{ OXA $\left(\mathrm{g} \mathrm{ha}^{-1}\right)$} \\
\hline 1993 & 58.1 & 30.4 & 39.0 & 32.6 & 43.5 & 16.7 & 28.4 & 22.0 & 35.2 \\
\hline 1994 & 7.4 & 2.4 & 3.0 & 2.7 & 4.3 & 1.3 & 1.8 & 2.3 & 1.9 \\
\hline 1995 & 42.4 & 7.5 & 9.0 & 8.3 & 10.0 & 3.6 & 4.9 & 4.9 & 6.5 \\
\hline Total & 108.0 & 40.3 & 51.0 & 43.6 & 57.8 & 21.6 & 35.1 & 29.2 & 43.6 \\
\hline
\end{tabular}

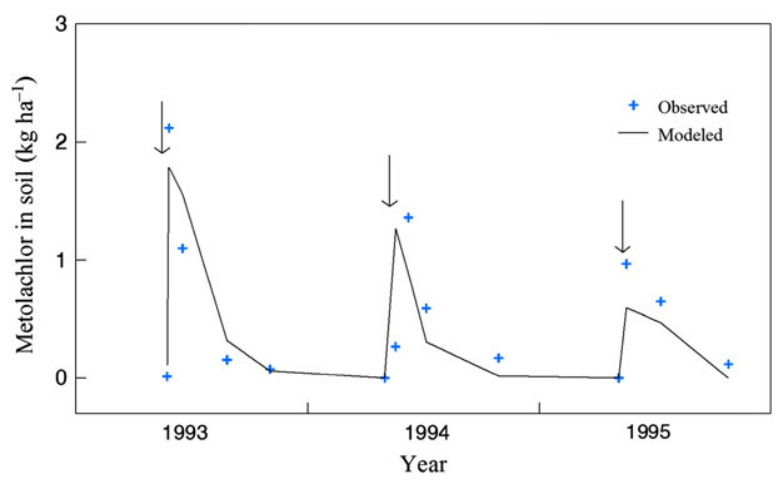

Figure 2. Observed and RZWQM-predicted metolachlor in the soil profile in chisel-tilled plot 13 in Nashua, lowa. Arrows denote the date of herbicide application.

with the observations of Kolpin et al. ${ }^{18}$ that metolachlor metabolites are more frequently detected in groundwater in lowa than the parent compound.

Unlike the two surface-applied herbicides, which are immediately available for transport, OXA must first be formed as a result

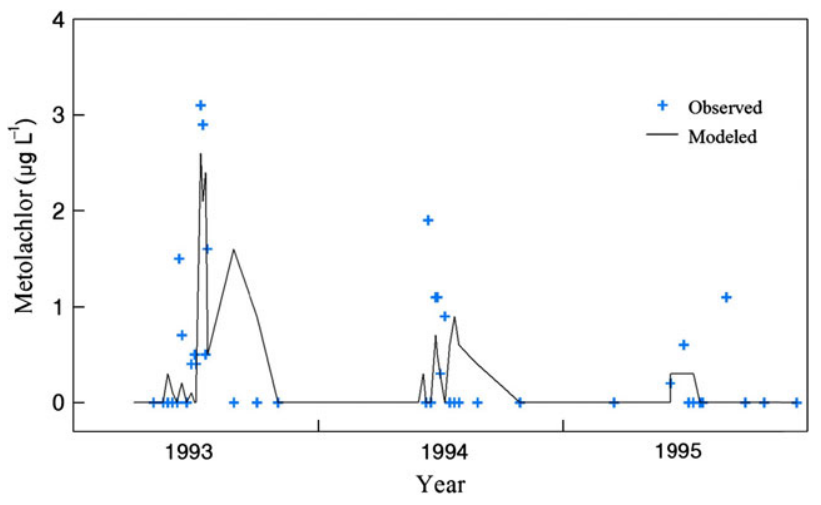

Figure 3. Weekly averaged observed and RZWQM-predicted metolachlor concentration in subsurface drainage from chisel-tilled plot 13 in Nashua, lowa.

of metolachlor degradation. In 1993, the year with greatest transport (Table 3), the RZWQM indicated that the OXA concentration in soil peaked around 6 July (Fig. 5), about 50 days after metolachlor application. This is similar to the 56 days it took for OXA 


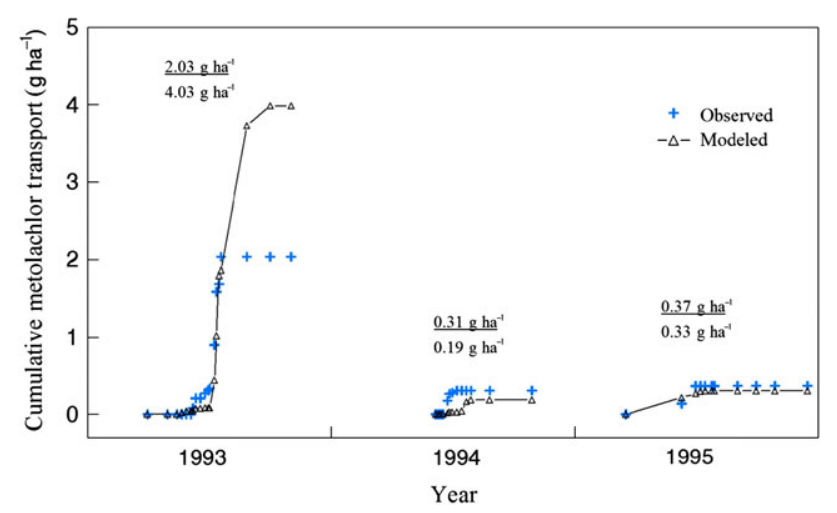

Figure 4. Cumulative metolachlor transport in subsurface drainage from chisel-tilled plot 13 in Nashua, lowa. The top number above each year is the measured annual transport, with the modeled amount beneath.

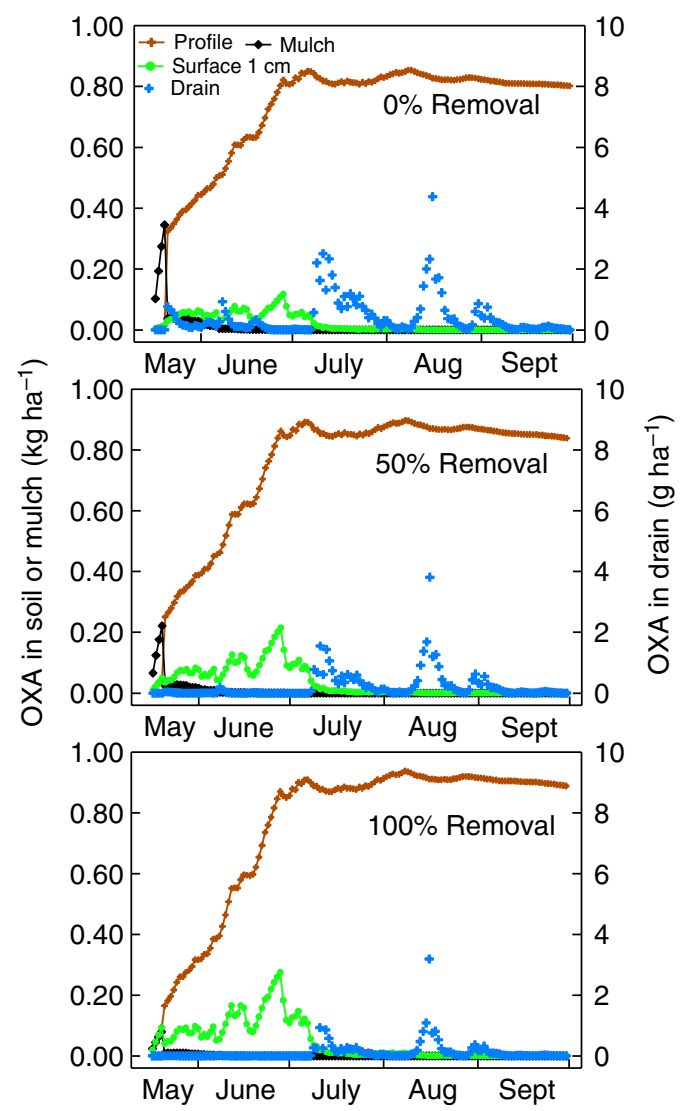

Figure 5. Simulated daily distribution of OXA on the surface mulch, surface $1 \mathrm{~cm}$ of soil, in the soil profile and in tile drainage in Nashua, lowa, chisel-tilled plot 13 as a function of residue removal rate from 17 May 1993 to 1 October 1993.

concentrations to peak in soil incubation studies, ${ }^{35}$ suggesting that our model reasonably simulated OXA formation and degradation.

Removal of the residue at the $50 \%$ level, with no change in soil hydraulic properties, resulted in a $63-67 \%$ decrease in average atrazine, metolachlor and OXA losses in subsurface drainage compared with leaving the residue intact while drainage volume was only reduced $31 \%$ (Table 3 ). Likewise, predicted losses of these compounds were further decreased when surface biomass removal was increased to $100 \%$. As was observed with drainage volume, removal of the first $50 \%$ of stover had a much greater effect than removal of the remaining residue. The observation that predicted reductions in chemical transport were much greater than predicted reductions in drainage volume suggested that residue removal increased sorption because of greater direct contact with the soil, resulting in reduced transport into macropores.

A closer examination of the distribution of metolachlor on the soil and residue with time and losses in tile flow supports this contention (Fig. 6). Data for 1993, when most metolachlor transport to drainage occurred, indicated that immediately after herbicide application on 17 May there was more metolachlor on the residue when no harvest took place and progressively less with $50 \%$ and $100 \%$ residue removal. Conversely, the amount on the surface $1 \mathrm{~cm}$ of soil was greatest with $100 \%$ residue removal and least with no removal. This immediate contact with the soil enhanced metolachlor sorption and reduced availability for transport. Consequently, the first rainfall after herbicide application on 21 May resulted in $5.0 \mu \mathrm{g} \mathrm{cm}^{-2}$ of metolachlor transport in macropores when the residue was intact, but only $2.1 \mu \mathrm{g} \mathrm{cm}-2$ with $100 \%$ residue removal.

Generally speaking, metolachlor was rapidly removed from the residue for all harvest levels, but concentrations in the upper $1 \mathrm{~cm}$ of soil remained consistently higher with residue removal. At the time when major rainfall-induced movement of water to the drain occurred (e.g. 11 July and 16 August 1993), metolachlor concentrations at depth in the profile were slightly greater with no residue removal than when residue was harvested (Fig. 7). In addition, the water table was higher when the residue was left intact on account of reduced evaporation (Fig. 6). When the water table reached this zone, metolachlor was available to be mobilized and transmitted to the drain. ${ }^{28}$ These factors contributed to more metolachlor transport to the drains when no residue was removed.

\subsection{Combined effect of residue harvest and changes in soil hydraulic properties on herbicides in tile flow}

It is unlikely, however, that residue removal would not affect soil hydraulic properties. For example, Blanco-Canqui et al. ${ }^{7}$ noted that 1 year after removing $100 \%$ of the corn stover there was a 7-31-fold reduction in soil saturated hydraulic conductivity at 0-20 cm depth that was dependent on soil type. In a follow-up study 2.5 years after beginning stover removal, they noted that, when more than $50 \%$ was removed, initial water infiltration was reduced 2-4-fold for silt loam soils, but not significantly changed for a clay loam soil. ${ }^{36}$ They attributed this loss of hydraulic function to sealing and crusting of the soil surface, caused by reduced protection from raindrop impact and fewer earthworm-formed macropores. Additional weight and frequency of traffic related to mechanically harvesting the stover can further contribute to increased soil compaction and decreased infiltration, ${ }^{37}$ which was not a factor in the plots of Blanco-Canqui and $\mathrm{Lal}^{36}$ where corn stover was removed by hand. Thus, while the $25 \%$ reductions in surface crust conductivity and soil macroporosity we selected at the $50 \%$ stover removal rate and the $50 \%$ reductions at $100 \%$ stover harvest rate were somewhat arbitrary, these reductions are reasonable and likely to be conservative based on available literature.

Separately, the $25 \%$ reduction in surface crust conductivity and soil macroporosity at the $50 \%$ residue removal rate increased losses of the three compounds in drainage by a similar amount (Table 3). For example, total atrazine loss increased from 0.93 to $2.71 \mathrm{~g} \mathrm{ha}^{-1}$ when crust conductivity was reduced, and to 2.23 $\mathrm{g} \mathrm{ha}^{-1}$ when macroporosity was reduced. Predicted losses of atrazine and metolachlor under these scenarios were similar to 


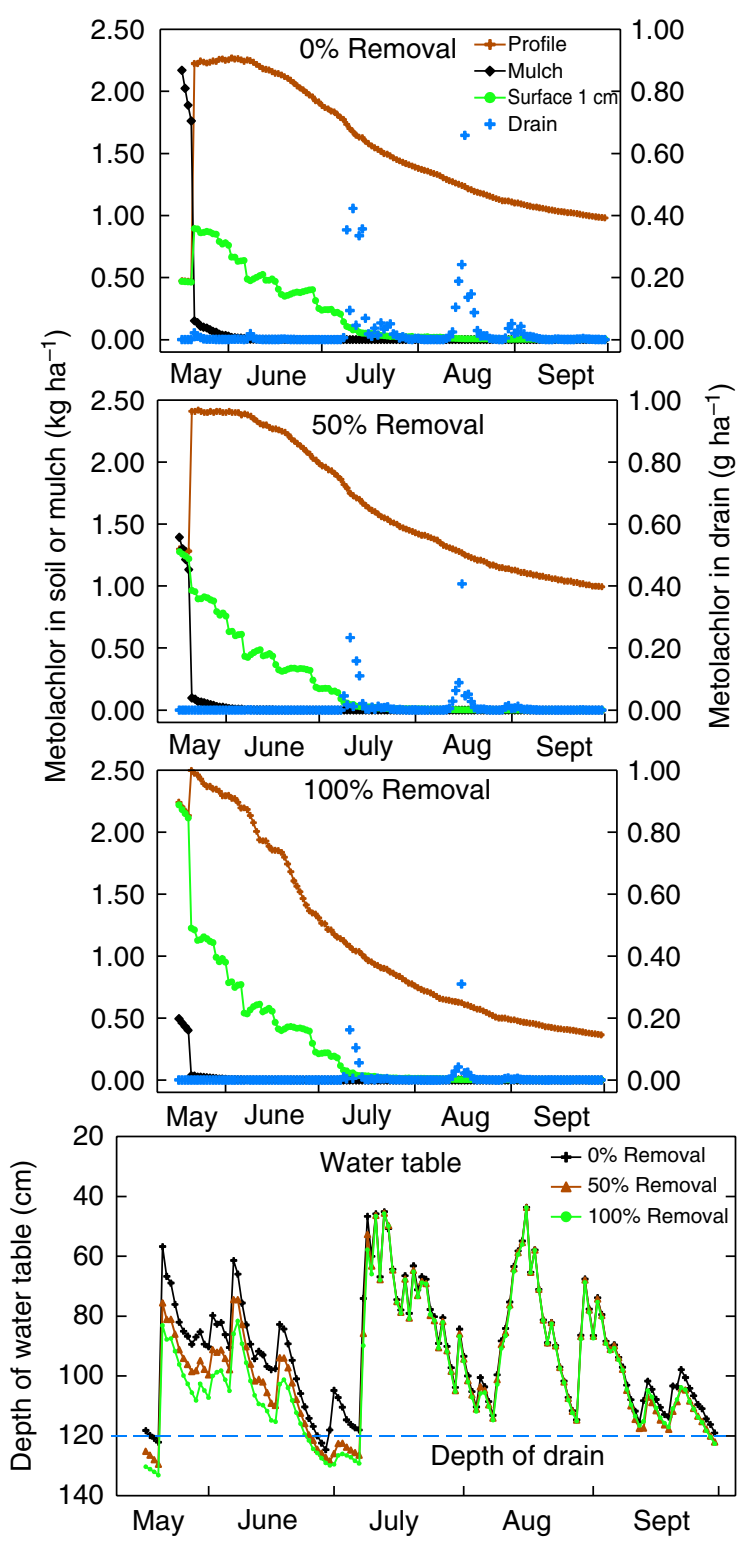

Figure 6. Simulated daily distribution of metolachlor on the surface mulch, surface $1 \mathrm{~cm}$ of soil, in the soil profile and in tile drainage and the depth of the water table in Nashua, lowa, chisel-tilled plot 13 as a function of residue removal rate from 17 May 1993 (date of application) to 1 October 1993.

predicted losses when no residue was removed $\left(2.54 \mathrm{~g} \mathrm{ha}^{-1}\right)$. Predicted losses of OXA, however, were only about one-half of those predicted with no residue removal. When the $100 \%$ residue removal scenario was invoked along with separate $50 \%$ reductions in surface crust conductivity and soil macroporosity, average losses of atrazine and metolachlor were greater than those predicted with no residue removal. In contrast, predicted OXA losses were less than those with either no residue removal or $50 \%$ removal. Thus, while reducing surface crust conductivity and soil macroporosity increased losses of herbicides compared with no residue removal, it had the opposite effect on losses of the degradation product.

In the last scenario, when surface crust conductivity and soil macroporosity were simultaneously reduced, predicted losses of both herbicides increased substantially compared with when each parameter was adjusted separately (Table 3 ). At the $50 \%$ residue removal rate, atrazine losses were fourfold greater and metolachlor losses were increased fivefold compared with their losses when the residue was not removed. Similarly the $100 \%$ residue removal rate further increased losses of these herbicides. Losses of OXA, however, were only slightly increased compared with scenarios where surface crust conductivity and soil macroporosity were reduced separately. In addition, the maximum predicted loss of OXA was less than half the loss when the residue was not removed. Thus, removing the residue and changing the hydraulic properties to reflect an increase in soil surface crusting and a decrease in soil macroporosity greatly increased losses of atrazine and metolachlor while decreasing total tile flow.

Most of the increased parent compound losses with reduced hydraulic properties were due to diminished ability of macropore linings to sorb these compounds as the amount of water, atrazine and metolachlor transmitted by individual macropores increased. When surface crust conductivity is reduced, the RZWQM simulates less infiltration into the soil matrix and more water and herbicide transport into macropores.

In our simulations when residue was removed, the number of active macropores $\left(N_{\mathrm{mac}}\right)$ decreased and less of the soil matrix was available to contribute to herbicide sorption, resulting in increased transport through macropores. As discussed by Malone et al., ${ }^{20,28}$ more herbicide can leach with a smaller $N_{\text {mac }}$ because water and chemicals transported into macropores are distributed between fewer macropores than with a larger $N_{\text {mac }}$. Therefore, less soil was available for chemical partitioning per mass of chemical for the residue removal plots when $N_{\text {mac }}$ was reduced.

Experimentally, Stehouwer et al. ${ }^{38}$ demonstrated that, even with rapid, non-equilibrium flow, macropore linings were able to sorb $46-93 \%$ of the introduced atrazine and metolachlor, with higher sorption percentages noted for earthworm burrows than for artificial macropores of similar diameter. When Edwards et al. ${ }^{39}$ sequentially added aliquots of water containing atrazine to artificial macropores, however, they noted that the atrazine concentration in water exiting macropores progressively increased, which they attributed to partial saturation of sorption sites. Likewise, Farenhorst et al. ${ }^{40}$ attributed increased transport of atrazine and metolachlor in earthworm burrows with time to rapid saturation of sorption sites on the burrow wall.

Reduced OXA transport with residue removal and no changes in soil properties was attributable to the same phenomena as those observed with metolachlor. That is, less transport into macropores in 1993 shortly after application and less OXA at or deeper than the water table during the July and August tile flow. Decreased formation shortly after application owing to slower metolachlor breakdown in soil compared with mulch was probably also a contributing factor. For example, on 23 May 1993, $0.41 \mathrm{~kg} \mathrm{OXA} \mathrm{ha}^{-1}$ was available with no residue removal compared with $0.21 \mathrm{~kg} \mathrm{ha}^{-1}$ in $100 \%$ removal (Fig. 5). These factors contributed to more OXA being available in the vicinity of the water table when leaching occurred (Fig. 7). Just before the major rainfall-induced leaching event on 11 July 1993, the total amount of OXA below $40 \mathrm{~cm}$ in the soil profile was $0.092 \mathrm{~kg} \mathrm{ha}^{-1}$ with no residue removal, whereas less than half the amount (i.e. $0.035 \mathrm{~kg} \mathrm{ha}^{-1}$ ) was present when $100 \%$ of the residue was removed (Fig. 7).

In the case of OXA, reduced losses in tile flow with residue removal and changed hydraulic properties were primarily the result of its lower $K_{\text {oc }}\left(57 \mathrm{~mL} \mathrm{~g}^{-1}\right)$ compared with metolachlor (200 $\mathrm{mL} \mathrm{g}^{-1}$ ). If we hypothetically increased its $K_{\mathrm{oc}}$ in the simulations to $200 \mathrm{~mL} \mathrm{~g}^{-1}$, OXA loss in drainage for the 3 year period was 16.1 $\mathrm{g} \mathrm{ha}^{-1}$ with $100 \%$ residue removal and reduced conductivity and 

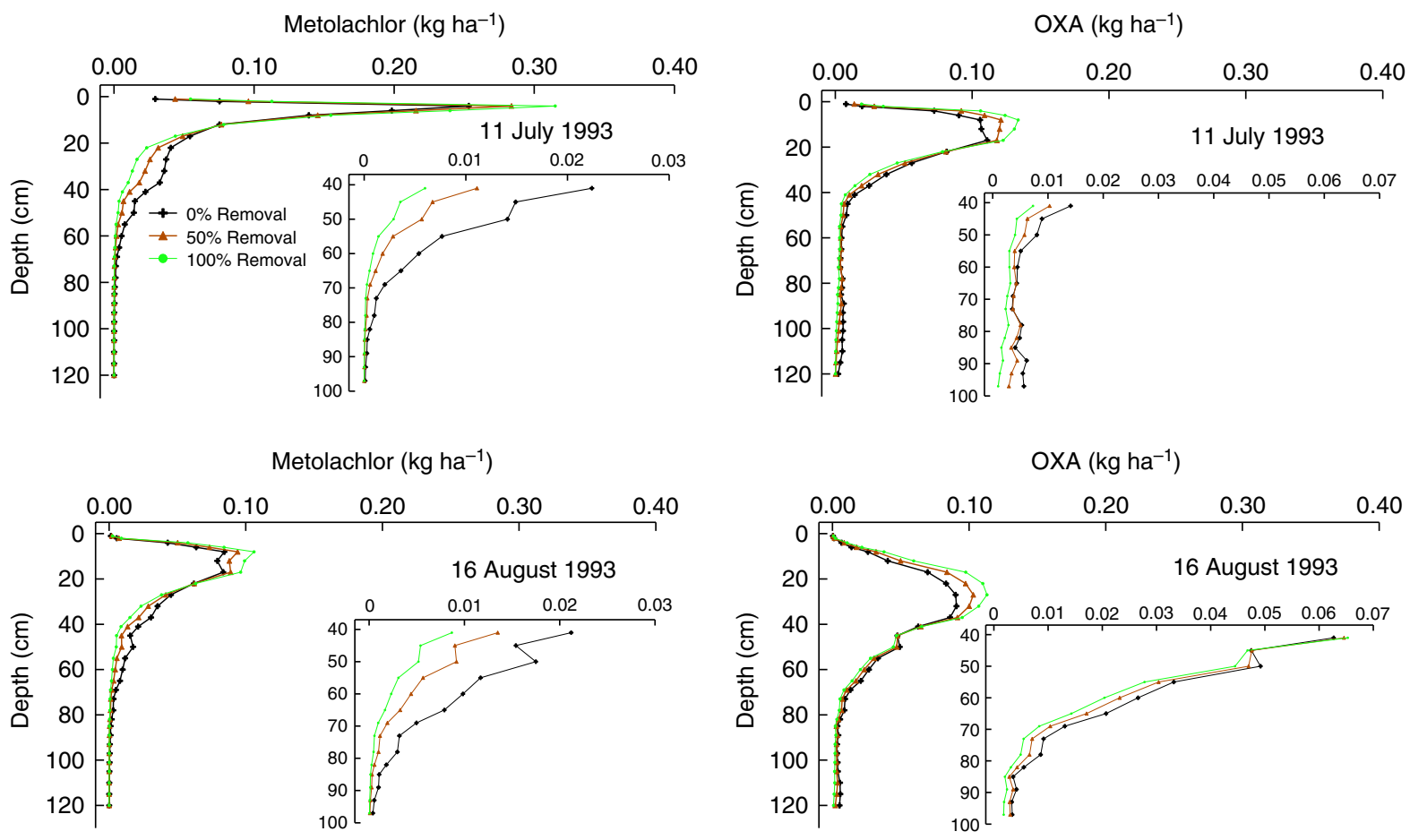

Figure 7. Simulated depth distribution of metolachlor and OXA in the soil profile in Nashua, lowa, chisel-tilled plot 13 on 11 July and 16 August 1993 as a function of residue removal rate. The insets zoom on the concentrations from 40 to $100 \mathrm{~cm}$.

macroporosity, as opposed to $6.8 \mathrm{~g} \mathrm{ha}^{-1}$ with no residue removal and the original soil hydraulic properties. Likewise, in 1993 with the increased $K_{\mathrm{oc}}$ OXA transport $\left(12.5 \mathrm{~g} \mathrm{ha}^{-1}\right)$ was much greater with $100 \%$ residue removal and changed soil hydraulic properties than with no residue removal and the original hydraulic properties ( 2.3 $\left.\mathrm{g} \mathrm{ha}^{-1}\right)$.

\section{SUMMARY AND CONCLUSIONS}

The RZWQM results matched the measured tile flow and herbicide transport fairly accurately. In addition, simulated formation of OXA was similar to values reported in the literature. These observations suggest that the model can be used with confidence to predict the effect of residue removal on herbicide and metabolite transport. In all scenarios, residue removal reduced the volume of tile flow, with the first $50 \%$ increment in residue removal having a larger relative effect than removing the remaining $50 \%$. It is unlikely, however, that $100 \%$ residue removal will become a standard practice, given the known negative effects on soil organic matter content and increased risk of surface run-off and soil erosion. On the other hand, partial removal of corn stover can increase crop yields in regions with cool, temperate climates and poorly drained soils. ${ }^{36}$ It is also unlikely that residue removal would not concurrently alter the soil hydrological properties. Thus, the most likely scenario of those we simulated is 50\% residue removal with reduced crust conductivity and reduced soil macroporosity. Under this scenario, the model predicts that residue harvest will result in sufficient remaining residue to maintain soil health in most years (i.e. $>6000 \mathrm{~kg}$ $\left.\mathrm{ha}^{-1}\right)$, but will substantially (4-5-fold) increase losses of atrazine and metolachlor in tile drainage with only modest (25\%) reductions in crust conductivity and soil macroporosity. Increased loss of these materials was attributable to their reduced sorption due to more total flow moving through fewer macropores. Even under this scenario, the maximum estimated amount of herbicide transmitted to tile drains on an annual basis ( $0.9 \%$ of the applied metolachlor in 1993) was well within the norms of field observations. In their comprehensive review, Kladivko et al. ${ }^{41}$ noted that mass losses of pesticides in tile drainage are generally less than $1 \%$, but can be a high as $3 \%$.

In contrast to herbicide losses, the model under all scenarios predicted that residue harvest will reduce the loss of the metolachlor degradation product OXA. As this degradate is formed after herbicide application, more rapid movement of the parent compound into the soil matrix by intervening rainfalls, which is a consequence of residue harvest, should make the degradate positionally less available to be transported by macropore flow to tile drains. Regardless, OXA losses to tile flow were greater than losses of metolachlor as a percentage of the amount of the parent compound applied, which is consistent with the observations of Kolpin et al. ${ }^{18}$ with regard to the relative proportions of metolachlor and its degradates detected in lowa groundwater.

Field studies are necessary to confirm model simulations. One of the primary values of numerical models is to illuminate aspects of a system that are most in need of further study. ${ }^{42}$ Nevertheless, our simulations indicated that corn stover harvest, even with only $50 \%$ removal, can negatively impact drainage water quality.

\section{ACKNOWLEDGEMENTS}

We thank Pat Bartling (USDA-Agricultural Research Service, Fort Collins, CO) for working with us to update the RZWQM code so that it can address the fate of pesticide degradation products.

\section{REFERENCES}

1 Perlack RD and Stokes BJ, U.S. Billion-Ton Update: Biomass Supply for a Bioenergy and Bioproducts Industry. [Online]. 
ORNL/TM-2011/224, Oak Ridge National Laboratory, US Department of Energy, Oak Ridge, TN (2011). Available: http://www1.eere. energy.gov/bioenergy/pdfs/billion_ton_update.pdf [28 May 2015].

2 Keeler BL, Krohn BJ, Nickerson TA and Hill JD, U.S. Federal agency models offer different versions for achieving Renewable Fuel Standard (RFS2) biofuel volumes. Environ Sci Technol 47:10 095-10 101 (2013).

3 Karlen DL and Johnson JMF, Crop residue considerations for sustainable bioenergy feedstock supplies. BioEnergy Res 7:465-467 (2014).

4 Blanco-Canqui $\mathrm{H}$ and Lal $\mathrm{R}$, Crop residue removal impacts on soil productivity and environmental quality. Crit Rev Plant Sci 28:139-163 (2009).

5 Lal R, Is crop residue a waste? J Soil Water Conserv 59(6):136A-139A (2004).

6 Wilhelm WW, Johnson JMF, Karlen DL and Lightle DT, Corn stover to sustain soil organic carbon further constrains biomass supply. Agron J 99:1665-1667 (2007).

7 Blanco-Canqui H, Lal R, Post WM, Izaurralde RC and Shipitalo MJ, Soil hydraulic properties influenced by corn stover removal from no-till corn in Ohio. Soil Tillage Res 92:144-155 (2007).

8 Sheehan J, Aden A, Paustian K, Killian K, Brenner J, Walsh M et al., Energy and environmental aspects of using corn stover for fuel ethanol. J Ind Ecol 7(3-4):117-146 (2003).

9 Butt KR, Shipitalo MJ, Bohlen PJ, Edwards WM and Parmelee RW, Long-term trends in earthworm populations of cropped experimental watersheds in Ohio, USA. Pedobiologia 43:713-719 (1999).

10 Edwards CA and Bohlen PJ, Biology and Ecology of Earthworms. 3rd edition. Chapman and Hall, London, UK, 426 pp. (1996).

11 Karlen DL, Wollenhaupt NC, Erbach DC, Berry EC, Swan JB, Eash NS et al., Crop residue effects on soil quality following 10-years of no-till corn. Soil Tillage Res 31:149-167 (1994).

12 Shipitalo MJ, Dick WA and Edwards WM, Conservation tillage and macropore factors that affect water movement and the fate of chemicals. Soil Tillage Res 53:167-183 (2000).

13 Beven K and Germann P, Macropores and water flow in soils. Water Resour Res 18(5):1311-1325 (1982).

14 Gilliom RJ, Barbash JE, Crawford CG, Hamilton PA, Martin JD, Nakagaki $\mathrm{N}$ et al., The quality of our nation's waters - pesticides in the nation's streams and ground water, 1992-2001. Circular 1291, US Geological Survey, Reston, VA (2006).

15 Kolpin DW, Kalkhoff SJ, Goolsby DA, Sneck-Fahrer DA and Thurman EM, Occurrence of selected herbicide and herbicide degradation products in lowa's ground water, 1995. Ground Water 35(4):679-688 (1997).

16 Krutz LJ, Senseman SA, McInnes KJ, Hoffman DW and Tierney DP, Adsorption and desorption of metolachlor and metolachlor metabolites in vegetated filter strip and cultivated soil. J Environ Qual 33:939-945 (2004).

17 Reregistration Eligibility Decision (RED) Metolachlor. Report 738-R-95-006. [Online]. USEPA, Washington, DC (1995). Available: http://www.epa.gov/pesticides/reregistration/metolachlor/ [28 May 2015].

18 Kolpin DW, Thurman EM and Linhart SM, Finding minimal herbicide concentrations in ground water? Try looking for their degradates. Sci Total Environ 248:115-122 (2000).

19 Malone RW, Ahuja LR, Ma L, Wauchope RD, Ma Q and Rojas KW, Application of the Root Zone Water Quality Model (RZWQM) to pesticide fate and transport: an overview. Pest Manag Sci 60:205-221 (2004).

20 Malone RW, Weatherington-Rice J, Shipitalo MJ, Fausey N, Ma L, Ahuja LR et al., Herbicide leaching as affected by macropore flow and within-storm rainfall intensity variation: a RZWQM simulation. Pest Manag Sci 60:277-285 (2004).

21 Wauchope RD, Estes TL, Allen R, Baker JL, Hornsby AG, Jones RL et al., Predicted impact of transgenic, herbicide-tolerant corn on drinking water quality in vulnerable watersheds of the mid-western USA. Pest Manag Sci 58(2): $146-160$ (2002).

22 Ahuja LR, DeCoursey DG, Barnes BB and Rojas KW, Characteristics of macropore transport studied with the ARS Root Zone Water Quality Model. Trans ASAE 36(2):369-380 (1993).
23 Fox GA, Sabbagh GJ, Malone RW and Rojas, K, Modeling parent and metabolite fate and transport in subsurface drained fields with directly connected macropores J Am Water Resour Ass 43(6):1359-1372 (2007).

24 Nolan BT, Malone RW, Doherty JE, Barbash JE, Ma L and Shaner DL, Data worth and prediction uncertainty for pesticide transport and fate models in Nebraska and Maryland, United States. Pest Manag Sci DOI: 10.1002/ps.3875 (2014).

25 Heilman P, Kanwar RS, Malone RW, Ma L, Hatfield JL and Boyle K, The Nashua agronomic, water quality, and economic dataset. J Soil Water Conserv 67(6):502-512 (2012).

26 Kanwar RS, Colvin TS and Karlen DL, Ridge, moldboard, chisel, and no-till effects on tile water quality beneath two cropping systems. $J$ Prod Agric 10(2):227-234 (1997).

27 Kumar A, Kanwar RS and Ahuja LR, Evaluation of preferential flow component of RZWQM in simulating water and atrazine transport to subsurface drains. Trans ASAE 41(3):627-637 (1998).

28 Malone RW, Nolan BT, Ma L, Kanwar RS, Pederson C and Heilman $P$, Effects of tillage and application rate on atrazine transport to subsurface drainage: evaluation of RZWQM using a six-year field study. Agric Water Manag 132:10-22 (2014).

29 Doherty J, PEST: Model Independent Parameter Estimation User Manual, $5^{\text {th }}$ edition. [Online]. Watermark Numerical Computing, Brisbane, Australia (2005). Available: http://www.pesthomepage.org/Downloads.php [28 May 2015].

30 Shaner DL, Farahani HJ and Buchleiter GW, Predicting and mapping herbicide-soil partition coefficients for EPTC, metribuzin, and metolachlor on three Colorado fields. Weed Sci 56:133-139 (2008).

31 Wauchope RD, Rojas KW, Ahuja LR, Ma Q, Malone RW and Ma $\mathrm{L}$, Documenting the pesticide processes module of the ARS RZWQM agroecosystem model. Pest Manag Sci 60(3):222-239 (2004).

32 Malone RW, Ma L, Wauchope RD, Ahuja LR, Rojas KW, Ma Q et al., Modeling hydrology, metribuzin degradation and metribuzin transport in macroporous tilled and no-till silt loam soil using RZWQM. Pest Manag Sci 60:253-266 (2004).

33 Johnson JMF, Novak JM, Varvel GE, Stott DE, Osborne SL, Karlen DL et al., Crop residue mass needed to maintain soil organic carbon levels: can it be determined? BioEnergy Res 7:481-490 (2014).

34 Moriasi DN, Arnold JG, Van Liew MW, Bingner RL, Harmel RD and Veith TL, Model evaluation guidelines for systematic quantification of accuracy in watershed simulations. Trans ASABE 50(3):885-900 (2007).

35 Mersie W, McNamee C, Seybold C, Wu J and Tierney D, Degradation of metolachlor in bare and vegetated soils and in simulated water-sediment systems. Environ Toxicol Chem 23:2627-2632 (2004).

36 Blanco-Canqui $\mathrm{H}$ and Lal $\mathrm{R}$, Soil and crop response to harvesting corn residues for biofuel production. Geoderma 141:355-362 (2007).

37 Wilhelm WW, Johnson JMF, Hatfield JL, Voorhees WB and Linden DR, Crop and soil productivity response to corn residue removal: a literature review. Agron J 96:1 - 17 (2004).

38 Stehouwer RC, Dick WA and Traina SJ, Sorption and retention of herbicides in vertically oriented earthworm and artificial burrows. J Environ Qual 23:286-292 (1994).

39 Edwards WM, Shipitalo MJ, Traina SJ, Edwards CA and Owens LB, Role of Lumbricus terrestris (L.) burrows in quality of infiltrating water. Soil Biol Biochem 24(12):1555-1561 (1992).

40 Farenhorst A, Topp E, Bowman BT, Tomlin AD and Bryan RB, Sorption of atrazine and metolachlor by burrow linings developed in soils with different crop residues at the surface. J Environ Sci HIth B 36(4):389-396 (2001).

41 Kladivko EJ, Brown LC and Baker JL, Pesticide transport to subsurface tile drains in humid regions of North America. Crit Rev Environ Sci Technol 31(1):1-62 (2001).

42 Oreskes N, Shraderfrechette K and Belitz K, Verification, validation, and confirmation of numerical-models in the earth-sciences. Science 263(5147):641-646 (1994). 